\title{
Critical sampling in the cement industry: economic drivers Martin Lischka
}

HERZOG Maschinenfabrik GmbH \& Co. KG, Germany

The total global cement production in 2020 was around 4.1 billiontons, making it the industrial processes sector responsible for the highest single contribution of emitted $\mathrm{CO}_{2}$ worldwide, with no less than $27 \%$ of the directly industrial-released $\mathrm{CO}_{2} \cdot{ }^{\cdot}$ Modern rotary kilns in cement plants have a production capacity of 5000-10,000t per day, and for each ton of clinker produced, $\sim 910 \mathrm{kgCO}_{2}$ are emitted to the atmosphere. ${ }^{2}$ These emissions stem from three main sources: i) decarbonisation of limestone, ii) fuel for

DOI: $10.1255 /$ sew.2021.a34
(c) 2021 The Author
Published under a Creative Commons
BY-NC-ND licence
CC) $\$$ BY

\section{Technical Info Box}

Compared to many traditional mining and minerals processing industries based on heterogeneous mineralisations and materials (e.g. base metals, gold ores), cement production is based on relatively homogeneous raw materials (clay, limestone), supplemented by a few aggregates to ensure consistent product quality. Traditionally, therefore, rather less attention has been paid to the strictness of the TOS within this industry. Sampling of the clinker is typically performed from the running process stream with a cycle of one sample per hour. After sampling, the clinker is coarsely crushed in a jaw crusher to a grain size of less than $5 \mathrm{~mm}$. This allows representative sampling to reduce the sample quantity to approximately $100 \mathrm{~g}$. In modern plants, samples are transported to the laboratory by pneumatic transportation. In the laboratory, sub-samples are finely ground $(<45 \mu \mathrm{m})$ and prepared for automated $X$-ray fluorescence (XRF) and X-ray diffraction (XRD) analysis. To be able the rotary kiln and iii) fuel for the electricity consumption of the cement plant. There is a vital sampling role hidden away in this big picture, illustrated here with five scenarios for a critical process control parameter termed "LSF" (Lime Saturation Factor), the economic impact of which is the main focus here.

\section{$\mathrm{CO}_{2}$ budgets}

In order to meet international agreements on climate change targets, and with introduction of " $\mathrm{CO}_{2}$ certificate trading" in Europe in 2005, in addition to diligent process control, a new aspect for successful and economic cement plant operation arises. Due to $\mathrm{CO}_{2}$ certificate trading, the importance of reliable sampling in cement production must be considered from the point of view of the lowest possible $\mathrm{CO}_{2}$ production and the highest possible reliability of

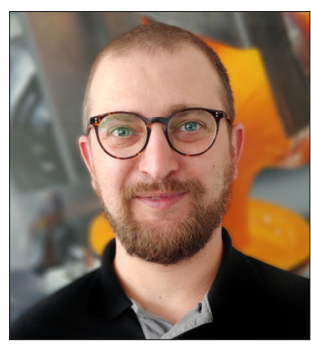

the data obtained. ${ }^{3}$ Studies have shown ${ }^{4}$ that a $5 \%$ variation in the single most important process monitoring parameter, LSF (see Technical Info Box), leads to an increase in $\mathrm{CO}_{2}$ emissions of up to $16.4 \mathrm{~kg} \mathrm{CO} / \mathrm{t}$ clinker. Likewise, $\mathrm{CO}_{2}$ emission from carbon-based fuels, by a similar $5 \%$ variation in LSF, increases by $17.2 \mathrm{kgCO}_{2} / \mathrm{t}$ clinker.

A sampling bias can very easily be introduced regarding the LSF, which can have severely amplified economic consequences.

\section{The economics of it all}

To illustrate the economic consequences of these technical relationships, one estimates the current financial impact based on a certificate price of $€ 55 \mathrm{t}^{-1} \mathrm{CO}_{2}$ (even to use automated analysers, only about $10-15 \mathrm{~g}$ of sample material is needed, which is pressed into a steel ring ( $\varnothing$ $51.5 \mathrm{~mm}$ ). Since the penetration depth of the analyser's X-rays is only a few micrometres, in reality only a very small portion of these few grams is analysed. It is obvious that sampling plays a critical role in this measuring system context. The effective sampling rate (clinker-toaliquot) is closely related to the clinker production rate (see Table 1) but can be estimated as 1:50,000,000-which under all circumstances is daunting.

However, the subsequent sample preparation also has a considerable influence on the analytical result. A measurable parameter for the quality of sub-sampling and sample preparation is the standard deviation, used as a measure of spread between replicated sampling and analysis results.

In addition to the classical elemental breakdown of chemical analysis, three so-called moduli are used in the cement industry for chemical classification. The most important of these is the so-called Lime Saturation Factor (LSF) which is calculated as follows: ${ }^{5}$

$$
\begin{gathered}
\mathrm{LSF}=100 \times \mathrm{CaO} / \\
\left(2.8 \times \mathrm{SiO}_{2}+0.65 \times \mathrm{Fe}_{2} \mathrm{O}_{3}+1.18 \times \mathrm{Al}_{2} \mathrm{O}_{3}\right)
\end{gathered}
$$

The three critical moduli are used to monitor and control the production targets. During the cement manufacturing process, heterogeneity of the intermediate products decreases continuously from the raw mixture to the finished product (good process control). The composition of the raw material mix and of the secondary fuels used are of significant importance for the clinker burning process efficiency, and also have a decisive influence on the composition of the clinker. Process control must, therefore, be carried out in such a way that the chemical and physical properties of the clinker remain as constant as possible. For this sensitive target, the quality, representativity and reliability of process sampling operations ARE of key importance. 


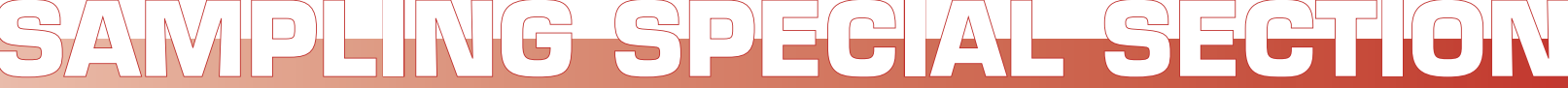

Table 1. Estimated additional $\mathrm{CO}_{2}$ release for different production capacities caused by erroneously determined LSFs and the financial impact in terms of $\mathrm{CO}_{2}$ certificate price trading. These certificate costs could be saved by running the cement plant with a well-controlled process close to product specifications and with optimised power consumption.

\begin{tabular}{|c|c|c|c|c|c|}
\hline & \multirow{2}{*}{$\begin{array}{l}\text { Rel error (\%) } \\
\text { LSF factor }\end{array}$} & \multicolumn{4}{|c|}{ Production in $\mathrm{t} /$ day } \\
\hline & & 1000 & 2000 & 5000 & 10,000 \\
\hline \multicolumn{6}{|c|}{ Additional release $\left(\mathrm{kg} \mathrm{CO}_{2} /\right.$ day $)$} \\
\hline \multirow{5}{*}{ Clinker } & 1 & 3280 & 6560 & 16,400 & 32,800 \\
\hline & 2 & 6560 & 13,120 & 32,800 & 65,600 \\
\hline & 3 & 9840 & 19,680 & 49,200 & 98,400 \\
\hline & 4 & 13,120 & 26,240 & 65,600 & 131,200 \\
\hline & 5 & 16,400 & 32,800 & 82,000 & 164,000 \\
\hline \multirow{5}{*}{ Fuel } & 1 & 3440 & 6880 & 17,200 & 34,400 \\
\hline & 2 & 6880 & 13,760 & 34,400 & 68,800 \\
\hline & 3 & 10,320 & 20,640 & 51,600 & 103,200 \\
\hline & 4 & 13,760 & 27,520 & 68,800 & 137,600 \\
\hline & 5 & 17,200 & 34,400 & 86,000 & 172,000 \\
\hline \multicolumn{6}{|c|}{ Estimated costs for $\mathrm{CO}_{2}$ certificate $(€)$} \\
\hline \multirow{5}{*}{ Day } & 1 & 370 & 739 & 1848 & 3696 \\
\hline & 2 & 739 & 1478 & 3696 & 7392 \\
\hline & 3 & 1109 & 2218 & 5544 & 11,088 \\
\hline & 4 & 1478 & 2957 & 7392 & 14,784 \\
\hline & 5 & 1848 & 3696 & 9240 & 18,480 \\
\hline \multirow{5}{*}{$\begin{array}{c}\text { Year } \\
\text { (300 days) }\end{array}$} & 1 & 110,880 & 221,760 & 554,400 & $1,108,800$ \\
\hline & 2 & 221,760 & 443,520 & $1,108,800$ & $2,217,600$ \\
\hline & 3 & 332,640 & 665,280 & $1,663,200$ & $3,326,400$ \\
\hline & 4 & 443,520 & 887,040 & $2,217,600$ & $4,435,200$ \\
\hline & 5 & 554,400 & $1,108,800$ & $2,772,000$ & $5,544,000$ \\
\hline
\end{tabular}

though increasing prices can be expected for the next years). The economic consequences of non-optimal LSF estimation are huge, as shown in Table 1. Here a relative error for the LSF ranging from 1\% to $5 \%$ is considered, correlated to the simulation data given by Cao et al. ${ }^{4}$ for typical daily production rates.

\section{Highly sensitive sampling}

It is very easy to introduce a significant variability in process monitoring and control if proper attention is not brought to bear-making representative process sampling essential. This can be illustrated for the same LSF parameter, based on XRF measurements. Results are presented below from an analysis repeatability test (10 analytical results from the an "accidental" higher amount of $\mathrm{Fe}_{2} \mathrm{O}_{3}$ which, however, changes the average LSF magnitude significantly, from 105.44 to 102.15 . This single sample preparation variation is consequently responsible for a relative error of $\sim 4 \%$ for the LSF, Table 2. With the economic impact of even small LSF variations as shown in Table 1, all sampling, sub-sampling and sample preparation variability is decidedly unwanted. TOS to the fore!

\section{Insight leads to greater} climate responsibility

The above economic relationships define three main goals for continuing vigilance regarding optimised cement production control to be in optimal compliance with increasingly stringent climate policy efforts, which today should be included in sustainability reports from all forwardlooking cement manufacturers:

- Process and product specifications, as close as possible to minimum climate impact demands

- Design of alternative, more climatefriendly cement products

- Low-energy operation and low- $\mathrm{CO}_{2}$ cement plant emissions

Thus, today there are both environmental, technological, economical (plant scale, global climate scale) as well as somewhat "hidden" sampling drivers for a continuously evolving cement industry-no longer mainly driven by narrow economic incentives alone. The TOS has a role to play nearly everywhere, and the economic costs for even a minor lassitude can be substantial, as was shown above (Table 1), in which a LSF uncertainty of $4 \%$ (rel) results in estimated potential additional certificate cost of $€ 4.4 \mathrm{M}$ per year.

There are other, non-optimised sampling issues in cement production, first and foremost primary clinker sampling. Often scoop sampling is applied in this stage, a sampling method that critically needs to be reconsidered, because a complete cross-section of the process stream is traditionally considered "almost impossible" to achieve. Remarkably there are not many publicly available clinker sampling rate estimates, nor assessments of the associated sampling errors.

\section{References}

1. IEA, Technology Roadmap Low-Carbon Transition in the Cement Industry. IEA, Paris (2018). https://www.iea.org/reports/technology-roadmap-low-carbon-transitionin-the-cement-industry [accessed 30 June 2021]

2. P. Stemmermann, U. Schweike, K. Garbev and G. Beuchle, "Celitement - a sustainable prospect for the cement industry", Cement Int. 8(5), 52-66 (2010). https://celitement.de/wp-content/ uploads/2020/07/2010-10-26 Celitement a sustainable prospect for the cement industry-1.pdf 


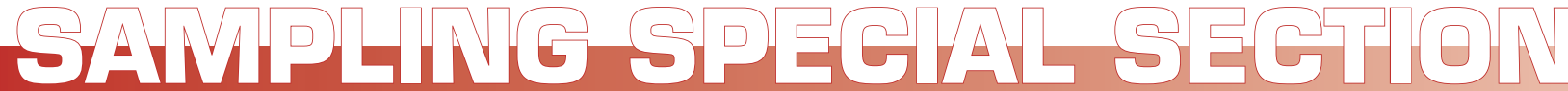

Table 2. Routine XRF analytical results from a simple replication experiment (10 analytical aliquots prepared from the same sample) showing how easily the LSF can be impacted by nonrepresentative sampling, preparation or analytical inconsistences. The primary clinker sampling variability must be added to this error, which is solely due to sample preparation and analysis.

\begin{tabular}{|c|c|c|c|c|c|}
\hline Test & $\mathrm{Al}_{2} \mathrm{O}_{3}$ & $\mathrm{SiO}_{2}$ & $\mathrm{CaO}$ & $\mathrm{Fe}_{2} \mathrm{O}_{3}$ & LSF \\
\hline $\mathbf{1}$ & 4.39 & 20.17 & 67.27 & 2.84 & 105.93 \\
\hline $\mathbf{2}$ & 4.38 & 20.19 & 67.21 & 2.81 & 105.78 \\
\hline $\mathbf{3}$ & 4.42 & 20.33 & 67.40 & 2.79 & 105.40 \\
\hline $\mathbf{4}$ & 4.41 & 20.33 & 67.41 & 2.80 & 105.41 \\
\hline $\mathbf{5}$ & 4.42 & 20.33 & 67.43 & 2.83 & 105.39 \\
\hline $\mathbf{6}$ & 4.43 & 20.24 & 67.33 & 2.79 & 105.67 \\
\hline $\mathbf{7}$ & 4.42 & 20.34 & 67.33 & 2.81 & 105.21 \\
\hline $\mathbf{8}$ & 4.44 & 20.39 & 66.63 & 4.48 & 102.15 \\
\hline $\mathbf{9}$ & 4.48 & 20.46 & 67.54 & 2.77 & 104.92 \\
\hline $\mathbf{1 0}$ & 4.46 & 20.38 & 67.51 & 2.81 & 105.26 \\
\hline Mean & 4.42 & 20.32 & 67.31 & 2.97 & \\
\hline SD & 0.03 & 0.08 & 0.25 & 0.50 & \\
\hline RSD & $0.6 \%$ & $0.4 \%$ & $0.4 \%$ & $16.9 \%$ & \\
\hline
\end{tabular}

3. C. Wagner and K.H. Esbensen, "A systematic approach to assessing measurement uncertainty for $\mathrm{CO}_{2}$ Emissions from coal-fired powerplants-missing contributions from the Theory of Sampling (TOS)", Chem. Eng. Res. Des. 89(9), 1572-1586 (2011). https://doi. org/10.1016/i.cherd.2011.02.028

4. Z. Cao, L. Shen, J. Zhao, L. Liu, S. Zhong and Y. Yang, "Modeling the dynamic mechanism between cement $\mathrm{CO}_{2}$ emissions and clinker quality to realize low-carbon cement", Resour. Conserv. Recy. 113, 116-126 (2016). https://doi.org/10.1016/i. resconrec.2016.06.011

5. VDZ, Zement Taschenbuch. Verein Deutscher Zementwerke (2008). https://www.vdz-online.de/ wissensportal?tx_vdzknowledgebase pi $1 \% 5$ Baction $\% 5 \mathrm{D}=$ detail\&tx vdzknowledgebase pi 1\%5Barticle preview $\% 5 D=6392 \& t x$ vdzknowledgebase pi $1 \% 5$ Bcontroller $\% 5 \mathrm{D}=$ Article\&tx vdzknowledgebase pi $1 \% 5$ Btype $\% 5$ $\mathrm{D}=0$ \&cHash $=790040$ ed0c 1 e $7 \mathrm{f3fd3}$ 5d7eaa91 c51373 [accessed 30 June 2021] 